\title{
Caracterização cultural, morfológica e patogênica de Lasiodiplodia theobromae associado a frutíferas tropicais
}

\author{
Joilson Silva Lima ${ }^{1}$, Renato Cesar Moreira ${ }^{1}$, José Emilson Cardoso², Marlon Vagner Valentim Martins ${ }^{2}$, Francisco \\ Marto Pinto Viana ${ }^{2}$
}

\begin{abstract}
${ }^{1}$ Departamento de Fitotecnia, Universidade Federal do Ceará, Av. Mister Hull, s/n - Campus do Pici, CEP 60 356-000, Fortaleza, CE; ${ }^{2}$ Embrapa Agroindústria Tropical, Rua Dra. Sara Mesquita, 2270 - Bairro do Pici, CEP 60 511-110, Fortaleza,CE.

Autor para correspondência: José Emilson Cardoso (jose-emilson.cardoso@embrapa.br)

Data de chegada: 29/07/2012. Aceito para publicação em: 20/02/2013.
\end{abstract}

\section{RESUMO}

Lima, J.S.; Moreira, R.C.; Cardoso, J.E.; Martins, M.V.V.; Viana, F.M.P. Caracterização cultural, morfológica e patogênica de Lasiodiplodia theobromae associado a frutíferas tropicais. Summa Phytopathologica, v.39, n.2, p.81-88, 2013.

Lasiodiplodia theobromae é um fungo cosmopolita, polífago e oportunista, com reduzida especialização patogênica, capaz de infectar espécies de plantas em regiões tropicais e temperadas, causando os mais variados sintomas. Este estudo teve como objetivo caracterizar isolados de L. theobromae associados a frutíferas tropicais na região nordeste, considerando os aspectos cultural, morfológico e patogênico. Foram avaliados o crescimento micelial, coloração da colônia, dimensões dos conídios e patogenicidade dos isolados em mudas de cajazeira (Spondia mombin L.), cajueiro (Anacardium occidentale L.), gravioleira (Annona muricata L.) e umbuzeiro (Spondias tuberosa Arruda). Os dados de caracterização morfológica e cultural revelaram diversidade na população do patógeno. Alta variabilidade patogênica foi também detectada, embora não tenha sido possível observar especificidade patogênica em cajueiro. O umbuzeiro apresentou maior resistência relativa ao fungo. Os dados demonstraram também uma interação entre as características morfo-culturais e a patogenicidade dos isolados de L. theobromae.

Palavras-chave adicionais: Cajueiro, graviola, Spondias, inoculação.

\section{ABSTRACT}

Lima, J.S.; Moreira, R.C.; Cardoso, J.E.; Martins, M.V.V.; Viana, F.M.P. Cultural, morphological and pathogenic characterization of Lasiodiplodia theobromae associated with tropical fruit plants. Summa Phytopathologica, v.39, n.2, p.81-88, 2013.

Lasiodiplodia theobromae is a cosmopolitan, polyphagous and opportunistic fungus with reduced pathogenic specialization, which is capable of infecting plant species in tropical and temperate regions, causing varied symptoms. This study aimed to characterize L. theobromae isolates associated with tropical fruit plants in Northeastern Brazil, considering their cultural, morphological and pathogenic characteristics. The evaluated aspects were mycelial growth, colony coloration, conidium dimension and pathogenicity of the isolates for seedlings of yellow mombin (Spondias mombin L.), cashew (Anacardium occidentale L.), soursop (Annona muricata L.), and Brazil plum (Spondias tuberosa Arruda). Data of morphological and cultural characterization revealed diversity in the pathogen population. High pathogenic variability was also detected, although no pathogenic specificity was found for cashew. Brazil plum showed higher relative resistance to the fungus. The data also demonstrated interaction between morphocultural characteristics and aggressiveness of $L$. theobromae isolates.

Additional keywords: Cashew, soursop, Spondias, inoculation.

Lasiodiplodia theobromae (Pat.) Griffon e Maubl. (syn. Botryodiplodia theobromae Pat.) é um fungo cosmopolita, polífago e oportunista, portanto, com reduzida especialização patogênica, infectando espécies de plantas em regiões tropicais e temperadas, causando os mais variados sintomas (22). É geralmente associado a processos patogênicos em plantas estressadas e submetidas a processos naturais ou provocados por insetos, pássaros, primatas nativos e pelo próprio homem, através de práticas culturais $(21,29)$.

Lasiodiplodia theobromae tem sido demonstrado capaz de colonizar tecidos de plantas sem exibir sintomas de infecção, característica típica de comportamento endofítico $(5,17,18)$. Uma das hipóteses é que esse fungo tenha evoluído da condição de endofitismo clássico para o parasitismo, em consequência de pressões ambientais, especialmente nas regiões semi-áridas, onde as condições climáticas, notadamente o estresse hídrico, favorecem a infecção (27). Corroborando esta idéia, verifica-se a crescente expansão das doenças causadas por L. theobromae em frutíferas tropicais, proporcionando inestimáveis perdas, tanto no sistema produtivo como em pós-colheita, representando uma ameaça à fruticultura no Nordeste $(8,11)$. A lista de hospedeiros e a severidade de ataque desse fitopatógeno também se têm verificado (12).

O controle das doenças causadas por L. theobromae torna-se bastante difícil, face às características ecológicas intrínsecas do fungo e a grande variedade de hospedeiros $(2,3,4,15,17,20)$. O manejo 
cultural e genético tem sido apontado como alternativas para algumas frutíferas hospedeiras desse patógeno $(2,4,28)$.

Variações morfológicas e culturais entre isolados de L. theobromae provenientes de diferentes regiões brasileiras são reportadas na literatura $(16,20,23)$. A necessidade de conhecimentos básicos sobre a biologia populacional e a interação do patógeno com as plantas hospedeiras servirão de subsídio para o estabelecimento de métodos de manejo ecológico e econômico das doenças causadas por esse fungo.

Este estudo teve como objetivo caracterizar uma população de $L$. theobromae associadas a frutíferas tropicais, cultivadas em diferentes regiões ecogeográficas do Nordeste brasileiro, avaliando-se o aspecto cultural, morfológico e patogênico.

\section{MATERIAL E MÉTODOS}

\section{Caracterização cultural e morfológica dos isolados}

Foram utilizados 16 isolados de L. theobromae disponíveis no Laboratório de Fitopatologia da Embrapa Agroindústria Tropical, obtidos originalmente em associação com diferentes sintomas, em diversos hospedeiros nos estados do Ceará, Maranhão e Piauí (Tabela 1).

Visando caracterizar o crescimento e esporulação dos isolados foram instalados dois experimentos: o primeiro em meio de cultura batata-dextrose-ágar (BDA), no qual se observou crescimento micelial e coloração das colônias; o segundo, em meio constituído de $2 \%$ de acículas de Pinus sp. autoclavadas e misturadas ao meio ágar (AP), onde foram anotados o crescimento da colônia e a morfologia dos conídios, após incubação a $28 \pm 1^{\circ} \mathrm{C}$, sob regime de alternância luminosa com fotoperíodo de $12 \mathrm{~h}$.

A avaliação do crescimento micelial foi constituída da medição do diâmetro da colônia em duas direções cruzadas, a cada 12 h, obtendose uma média para cada repetição. As medições foram concluídas quando o crescimento da colônia cobriu completamente o diâmetro da placa em um dos tratamentos, determinando-se a velocidade média de

Tabela 1. Caracterização dos isolados de Lasiodiplodia theobromae utilizados no estudo de diversidade cultural e morfológica.

\begin{tabular}{llll}
\hline No Isolado & Hospedeiro & Sintoma* & Origem \\
\hline L 01 & Cajaraneira & RS & Fortaleza-CE \\
L 06 & Coqueiro & PSF & Varjota-CE \\
L 16 & Cirigueleira & MD & Ipueiras-CE \\
L 32 & Cajueiro gigante & MD & Palmácia-CE \\
L 89 & Mangueira & MD & Varjota-CE \\
L 92 & Cajazeira & MD & Pires Ferreira-CE \\
L 97 & Cirigueleira & MD & Guaraciaba do Norte-CE \\
L 122 & Coqueiro & PBPC & Fortaleza-CE \\
L 153 & Gravioleira & MD & Trairi-CE \\
L 162 & Ateira & MD & Parambu-CE \\
L 165 & Umbuzeiro & MD & Pio IX-PI \\
L 177 & Umbu-cajazeiro & MD & Potengi-CE \\
L 183 & Cajueiro gigante & RS & Potiretama-CE \\
L 193 & Abacateiro & MD & Pio IX-PI \\
L 197 & Cajueiro gigante & PP H & Barra do Corda-MA \\
L 198 & Mamoeiro & P P & Paraipaba-CE \\
\hline
\end{tabular}

* $\mathrm{MD}=$ morte-descendente $; \mathrm{PBPC}=$ podridão-basal-pós-colheita; $\mathrm{PP}=$ podridão-dopedúnculo; $\mathrm{PPH}=$ podridão-preta-das-hastes; $\mathrm{PSF}$ = podridão-seca-das-folhas; $\mathrm{RS}=$ resinose. crescimento do fungo $(\mathrm{cm} / \mathrm{dia})$.

A coloração predominante da colônia (cinza claro $=\mathrm{CZC}$, cinza escuro $=$ CZE; preto $=$ PR) foi observada após 15 dias de incubação.

Utilizou-se, em ambos os ensaios, o delineamento experimental inteiramente casualizado (DIC) com quatro repetições, em que cada placa constituiu uma unidade experimental.

As dimensões dos conídios, considerando comprimento e largura, foram avaliadas após 25 dias de cultivo por microscopia óptica associada ao programa computacional para análise de imagens Motic Image Plus $2.0^{\circledR}$. Foram considerados o tamanho, variável que corresponde à soma do comprimento com a largura dos conídios, e a relação comprimento/largura. Foram avaliados 30 conídios por isolado de L. theobromae.

Os dados obtidos foram submetidos à análise de variância e as médias foram agrupadas pelo teste de Scott-Knott, ao nível de 5\% de significância, utilizando o programa estatístico Sisvar, versão 5.3, desenvolvido na Universidade Federal de Larvas.

\section{Caracterização patogênica dos isolados}

A patogenicidade dos isolados às mudas de cajazeira (Spondia mombin L.), cajueiro - clone CCP 76 (Anacardium occidentale L.), gravioleira (Annona muricata L.) e umbuzeiro (Spondia tuberosa Arruda) foi avaliada sob condições de casa de vegetação, onde a temperatura oscilou entre 25 a $30^{\circ} \mathrm{C}$ e a umidade relativa em torno de $70 \%$.

Cada espécie hospedeira, com oito meses de idade, constituiu um experimento, sendo que todos foram conduzidos em delineamento inteiramente casualizado (DIC). As plantas foram inoculadas com cada um dos 15 isolados, deixando-se um tratamento sem inocular como testemunha, totalizando 16 tratamentos por espécie hospedeira, com quatro repetições por tratamento, sendo cada repetição constituída por uma planta.

A inoculação das plantas com os isolados foi realizada em um orifício feito no caule, a $15 \mathrm{~cm}$ do colo e com cerca de $2 \mathrm{~mm}$ de profundidade, efetuado com auxílio de uma furadeira elétrica com broca de $2 \mathrm{~mm}$ de diâmetro.

Em cada orifício foi colocado um disco de BDA de $2 \mathrm{~mm}$ de diâmetro contendo micélio do fungo cultivado por sete dias, de modo que o isolado ficasse em contato com o sistema vascular da planta. Após a inoculação, o orifício foi fechado com vaselina sólida e envolvido com fita Parafilme ${ }^{\circledR}$. Nas plantas testemunhas foi inserido no orifício discos de BDA esterilizado.

A avaliação da agressividade dos isolados com base nos sintomas foi realizada 15 dias após a inoculação do fungo, através da medição do comprimento $(\mathrm{cm})$ das lesões internas observadas nas plantas, mediante corte longitudinal do caule das mudas.

Os dados coletados de cada hospedeiro foram transformados para $\sqrt{x+0,5}$ e submetidos à análise de variância. As médias foram agrupadas pelo teste de Scott-Knott ao nível de 5\% de significância utilizando o programa estatístico Sisvar.

A severidade dos sintomas foi avaliada com auxílio de uma escala de notas adaptada de Pereira et al. (20) que variou de 0 a 4, valores relacionados à severidade da doença: 0 - mudas sem lesão visível ( altamente resistente); 1 - lesão com até $3 \mathrm{~cm}$ de comprimento (resistente); 2 - lesão com até a $6 \mathrm{~cm}$ de comprimento (medianamente resistente); 3 - lesão de comprimento superior $6 \mathrm{~cm}$ (suscetível); 4 mudas com lesão profunda e abundante exsudação de resina, amarelecimento e queda de folhas ou mudas mortas (altamente suscetível).

Após a medição do comprimento das lesões, dois fragmentos de 
tecido do caule de cada muda, acima e abaixo do ponto de inoculação, totalizando oito pedaços do material lesionado, por tratamento, foram transferidos para placas de Petri contendo o meio ágar-água, visando comprovar a presença do patógeno nos tecidos infectados. Após 3 dias de incubação, o percentual de reisolamento foi anotado. Procedimento semelhante foi realizado a partir das mudas não inoculadas que constituíram o tratamento testemunha.

Os dados de crescimento micelial, dimensão do conídio, patogenicidade e altitude do pomar de origem dos isolados foram empregados em análises de correlação realizadas pelo método de Pearson.

\section{RESULTADOS E DISCUSSÃO}

\section{Caracterização cultural e morfológica dos isolados}

Os resultados das taxas médias de crescimento micelial para os isolados de Lasiodiplodia theobromae foram de 3,90 e 5,54 cm/dia, respectivamente, para os meios AP e BDA. Em ambos os meios de cultura, houve diferença estatística entre as médias de crescimento micelial dos isolados, ocorrendo também variação na coloração da colônia na população de fungos estudada cultivada em meio BDA, que variou de cinza claro a preto (Tabela 2). As variações entre isolados de L. theobromae referentes à taxa de crescimento micelial e coloração da colônia estão dentro dos limites obtidos por outros autores $(1,13,14$, 19, 20, 24).

Observou-se que a taxa de crescimento micelial de $L$. theobromae foi maior no meio BDA $(3,01 \mathrm{~cm} /$ dia a $6,54 \mathrm{~cm} /$ dia $)$ do que em AP $(1,96 \mathrm{~cm} /$ dia a $5,10 \mathrm{~cm} /$ dia $)$. Significativa variação entre isolados obtidos de uma mesma região e da mesma planta hospedeira foi observada, confirmando a grande variabilidade genética já relatada $(6,9,17)$. Os isolados causadores de morte-descendente da cirigueleira (L16-Ipueiras e L97-Guaraciaba do Norte) agruparam-se diferentemente para as variáveis crescimento micelial, em ambos os meios de cultura, e coloração da colônia. Taxas média de crescimento entre isolados de $L$. theobromae da mesma planta hospedeira foram referidas em outros estudos $(20,19)$. A maioria dos isolados apresentou colônias de coloração cinza escuro.

Os isolados de L. theobromae apresentaram conídios com dimensão média de 23,04 x 13,07 $\mu \mathrm{m}$, variando entre 18,10-30,94 x 10,64$15,86 \mu \mathrm{m}$. A relação comprimento/largura variou entre 1,52 e 2,26, com tamanho entre 29,54 e 46,80 $\mu \mathrm{m}$ (Tabela 3).

A relação comprimento/largura expressa a forma do conídio. Quanto maior o valor dessa variável, mais afilado (elipsóide) é a estrutura. Ao contrário, quanto menor este valor, mais arredondado (ovóide) é o conídio. Houve diferença estatística entre os dados dos isolados para comprimento, largura, relação comprimento/largura e tamanho de conídios, embora esses dados permitam colocar todos os isolados dentro da descrição original da espécie (21). Rodrigues (24) relata a variação dos conídios $L$. theobromae entre $(18-30)$ x $(10 \mathrm{x}$ 15) $\mu \mathrm{m}$, cultivados em cultura pura de BDA. Úrbez-Torres et al. (31) observaram que conídios de L. theobromae obtidos de plantas de videira mediam entre $22,1-28,8 \times 10,5-14,7 \mu \mathrm{m}$, com a razão comprimento/largura dos conídios variando entre 1,8 e 2,2. Observouse correlação positiva entre comprimento médio dos conídios de $L$. theobromae e as variáveis: largura de conídios, relação comprimento/ largura e tamanho dos esporos.

\section{Caracterização patogênica dos isolados}

Todos os quinze isolados de L. theobromae foram capazes de colonizar os tecidos dos hospedeiros testados, demonstrado pelo desenvolvimento de lesões quinze dias após a inoculação. Os sintomas observados foram: escurecimento do lenho, presença de goma e morte da planta (Figura 1). As plantas apresentaram pelo menos um desses

Tabela 2. Taxa de crescimento micelial e coloração da colônia de 16 isolados de Lasiodiplodia theobromae cultivados em meio AP e BDA.

\begin{tabular}{|c|c|c|c|c|}
\hline \multicolumn{2}{|c|}{ Crescimento micelial em $\mathbf{A P}^{1}$} & \multicolumn{3}{|c|}{ Crescimento micelial em $\mathbf{B D A}^{2}$} \\
\hline L 183 & $1,96 \mathrm{~A}$ & L 183 & $3,01 \quad \mathrm{~A}$ & PR \\
\hline L 97 & $2,43 \mathrm{~A}$ & L 97 & $3,16 \mathrm{~A}$ & CZE \\
\hline L 92 & $2,60 \mathrm{~A}$ & L 92 & 4,26 B & CZE \\
\hline L 153 & $3,20 \mathrm{~B}$ & L 122 & $5,08 \mathrm{C}$ & $\mathrm{CZE}$ \\
\hline L 193 & 3,69 B & L 89 & $5,59 \mathrm{D}$ & $\mathrm{CZE}$ \\
\hline L 122 & 3,77 B & L 198 & $5,75 \mathrm{D}$ & $\mathrm{PR}$ \\
\hline L 06 & 3,78 B & L 153 & $6,01 \quad \mathrm{E}$ & $\mathrm{PR}$ \\
\hline L 177 & $3,80 \quad \mathrm{~B}$ & L 32 & $6,04 \mathrm{E}$ & $\mathrm{CZE}$ \\
\hline L 165 & $4,56 \mathrm{C}$ & L 197 & $6,09 \mathrm{E}$ & CZE \\
\hline L 32 & $4,85 \mathrm{C}$ & L 177 & $6,49 \mathrm{~F}$ & CZE \\
\hline L 197 & $5,05 \mathrm{C}$ & L 193 & $6,51 \mathrm{~F}$ & $\mathrm{PR}$ \\
\hline L 16 & $5,10 \mathrm{C}$ & L 165 & $6,54 \mathrm{~F}$ & $\mathrm{CZC}$ \\
\hline Média & 3,90 & & 5,54 & \\
\hline $\mathrm{CV}(\%)$ & 9,66 & & 5,07 & \\
\hline
\end{tabular}

* Médias de 4 repetições por tratamento. Médias seguidas da mesma letra na coluna não diferem entre si pelo teste de Scott-Knott ao nível de $5 \%$ de significância; ${ }^{1}$ AP $=$ meio de cultura com $2 \%$ de acículas de Pinus sp. autoclavadas, misturadas ao meio Ágar; ${ }^{2} \mathrm{BDA}=$ batata-dextrose-ágar; ${ }^{3} \mathrm{CZC}=$ cinza claro, $\mathrm{CZE}=$ cinza escuro, $\mathrm{PR}=$ preto. 
Tabela 3. Características dos conídios de 16 isolados de Lasiodiplodia theobromae cultivados em meio AP.

\begin{tabular}{|c|c|c|c|c|c|c|c|}
\hline \multicolumn{2}{|c|}{ Comprimento } & \multicolumn{2}{|c|}{ Largura } & \multicolumn{2}{|c|}{ Relação $C / \mathbf{L}^{1}$} & \multicolumn{2}{|c|}{ Tamanho $^{2}$} \\
\hline Isolado & Média ${ }^{*}(\mu \mathbf{m})$ & Isolado & Média ${ }^{*}(\mu \mathrm{m})$ & Isolado & Média" & Isolado & Média $^{*}(\mu \mathrm{m})$ \\
\hline L 177 & $18,10 \mathrm{~A}$ & L 162 & $10,64 \mathrm{~A}$ & L 06 & $1,52 \mathrm{~A}$ & L 177 & $29,54 \mathrm{~A}$ \\
\hline L 01 & $19,05 \mathrm{~A}$ & L 01 & $11,53 \quad \mathrm{~B}$ & L 165 & $1,59 \mathrm{~A}$ & L 01 & $30,59 \mathrm{~A}$ \\
\hline L 06 & 20,19 B & L 122 & $11,67 \quad \mathrm{~B}$ & L 183 & $1,59 \mathrm{~A}$ & L 06 & $33,48 \quad$ B \\
\hline L 122 & $22,55 \mathrm{C}$ & L 193 & $12,88 \quad \mathrm{D}$ & L 197 & $1,67 \mathrm{~A}$ & L 193 & $35,84 \mathrm{C}$ \\
\hline L 193 & $22,96 \mathrm{C}$ & L 06 & $13,28 \quad \mathrm{D}$ & L 16 & $1,73 \quad \mathrm{~B}$ & L 165 & $35,92 \mathrm{C}$ \\
\hline L 197 & $23,07 \mathrm{C}$ & L 165 & $13,87 \quad \mathrm{E}$ & L 193 & $1,78 \quad \mathrm{~B}$ & L 183 & $36,42 \mathrm{C}$ \\
\hline L 162 & $24,12 \mathrm{D}$ & L 198 & $13,91 \quad E$ & L 198 & $1,80 \quad$ B & L 97 & $36,45 \mathrm{C}$ \\
\hline L 32 & $25,56 \mathrm{E}$ & L 16 & $14,08 \quad \mathrm{E}$ & L 97 & $1,97 \mathrm{C}$ & L 89 & $39,31 \quad \mathrm{D}$ \\
\hline L 92 & $30,94 \quad F$ & L 92 & $15,86 \mathrm{~F}$ & L 162 & $2,26 \mathrm{D}$ & L 92 & $46,80 \quad \mathrm{E}$ \\
\hline Média & 23,04 & & 13,07 & & 1,76 & & 36,12 \\
\hline CV (\%) & 7,36 & & 5,65 & & 9,39 & & 5,09 \\
\hline
\end{tabular}

* Médias de 30 repetições por tratamento. Médias seguidas da mesma letra na coluna não diferem entre si pelo teste de Scott-Knott ao nível de $5 \%$ de significância; ${ }^{1} \mathrm{C} / \mathrm{L}=$ relação comprimento/largura; ${ }^{2}$ Tamanho $=$ soma do comprimento com a largura de cada conídio.

sintomas em diferentes graus de desenvolvimento, comprovando a falta de especificidade patogênica de $L$. theobromae.

Os isolados L06 (originado do coqueiro), L153 (originado da gravioleira), L197 (originado do cajueiro) e L198 (originado do mamoeiro) foram os mais agressivos nos hospedeiros testados. Não foi observada nenhuma relação entre espécie hospedeira de origem e a patogenicidade do isolado, todavia, as Spondias (umbuzeiro e cajazeira) revelaram-se, de maneira geral, mais resistentes do que a gravioleira $\mathrm{e}$ o cajueiro (Tabela 4). Nenhum isolado demonstrou baixa capacidade patogênica a todos os hospedeiros testados, revelando uma capacidade

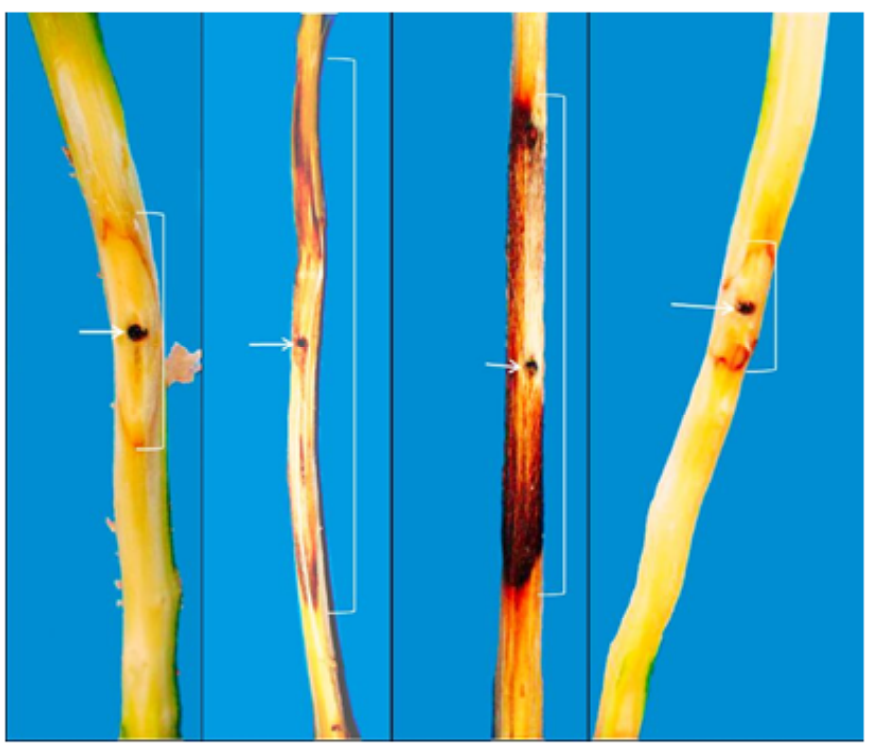

Figura 1. Na sequência, sintomas de infecção em mudas de cajazeira, cajueiro, gravioleira e umbuzeiro, inoculadas com Lasiodiplodia theobromae, destacando o ponto de inoculação e o desenvolvimento da lesão após quinze dias. patogênica eficiente e não especifica. Esse resultado foi semelhante ao obtido por Pereira et al. (20) para um isolado de mamoeiro que, inoculado em diferentes hospedeiros, mostrou-se patogênico a todos esses. Esses dados confirmam as informações anteriormente publicadas que reportam $L$. theobromae como um patógeno de ampla lista de hospedeiros, cuja patogenicidade está associada aos estresses do hospedeiro. Sendo as Spondias espécies nativas da região semi-árida, consequentemente adaptada às condições estressantes desse ambiente, é de se esperar uma maior resistência do umbuzeiro e cajazeira. Todavia, as variações de patogenicidade entre os isolados necessitam ser investigadas quanto às diferenças no mecanismo de infecção e os fatores de estresses que a induzem.

Embora todos os isolados demonstrassem capacidade de infectar os quatro hospedeiros, esses variaram quanto à suscetibilidade ao fungo (Tabela 4). A gravioleira foi a espécie mais suscetível, apresentando a maior média de comprimento de lesão $(17,04 \mathrm{~cm})$. Esses dados ratificam relatos de outros pesquisadores $(3,17,30)$ que definiram $L$. theobromae como um fungo cosmopolita, polífago e oportunista, com pouca especialização patogênica, considerado o principal agente do declínio precoce dos pomares de graviola, responsável pela frustração da maioria dos empreendimentos de produção dessa fruta no nordeste brasileiro.

O agrupamento de isolados por agressividade e por espécie hospedeira mostrou que esse não é um caráter discriminatório para a população desse fungo, pois apenas a gravioleira possibilitou um agrupamento com cinco grupos, enquanto a cajazeira e o umbuzeiro permitiram a constituição de dois grupos, e o cajueiro de apenas um grupo (Figura 2). Estes dados permitem concluir que a população de L. theobromae estudada detém uma grande capacidade patogênica interespecífica a tecidos.

O reisolamento do fungo de tecidos de plantas inoculadas comprovou o estabelecimento do patógeno na região lesionada. $\mathrm{O}$ 
Tabela 4. Patogenicidade de 15 isolados de Lasiodiplodia theobromae a 4 espécies hospedeiras, inoculados $15 \mathrm{~cm}$ acima do colo das plantas.

\begin{tabular}{|c|c|c|c|c|c|c|}
\hline \multirow{3}{*}{ Isolado $^{1}$} & \multirow{3}{*}{ Origem do isolado } & \multirow{3}{*}{ Altitude $^{2}(m)$} & \multicolumn{4}{|c|}{ Nota $^{*}$} \\
\hline & & & \multicolumn{4}{|c|}{ Hospedeiros $^{\text {** }}$} \\
\hline & & & $\mathbf{C} \mathbf{z}$ & $\mathbf{C} \mathbf{j}$ & $\mathbf{G r}$ & $\mathbf{U z}$ \\
\hline L 01 (Cajaraneira) - RS & Fortaleza-CE & 21 & 3 & 4 & 4 & 2 \\
\hline L 06 (Coqueiro) - PSF & Varjota-CE & 183 & 4 & 4 & 4 & 3 \\
\hline L 16 (Cirigueleira) - MD & Ipueiras-CE & 231 & 3 & 4 & 4 & 3 \\
\hline L 23 (Umbu-cajazeiro) - MD & Maranguape-CE & 80 & 2 & 4 & 4 & 2 \\
\hline L 42 (Mangueira) - MD & Serra do Mel-RN & 215 & 1 & 3 & 3 & 1 \\
\hline L 54 (Umbuzeiro) - MD & Quixadá-CE & 189 & 2 & 3 & 4 & 2 \\
\hline L 73 (Aceroleira) - MD & Pacajus-CE & 60 & 1 & 2 & 4 & 3 \\
\hline L 92 (Cajazeira) - MD & Pires Ferreira-CE & 237 & 4 & 3 & 3 & 1 \\
\hline L 153 (Gravioleira) - MD & Trairi-CE & 09 & 4 & 4 & 4 & 3 \\
\hline L 162 (Ateira) - MD & Parambu-CE & 484 & 3 & 3 & 4 & 2 \\
\hline L 175 (Cajueiro gigante) - MD & Parambu-CE & 484 & 1 & 4 & 2 & 1 \\
\hline L 183 (Cajueiro gigante) - RS & Potiretama-CE & 121 & 2 & 4 & 2 & 1 \\
\hline L 193 (Abacateiro) - MD & Pio IX-PI & 700 & 3 & 3 & 3 & 3 \\
\hline L 197 (Cajueiro gigante) - PPH & Barra do Corda-MA & 80 & 4 & 4 & 4 & 3 \\
\hline L 198 (Mamoeiro) - PP & Paraipaba-CE & 31 & 4 & 4 & 4 & 3 \\
\hline
\end{tabular}

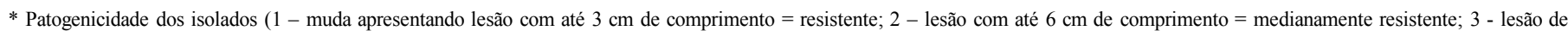
comprimento superior a $6 \mathrm{~cm}=$ suscetível; 4 - mudas com lesão profunda e abundante exsudação de resina, amarelecimento e queda de folhas ou mudas mortas = altamente suscetível); $* *$ Mudas hospedeiras inoculadas $\left(\mathrm{Cz}=\right.$ cajazeira; $\mathrm{Cj}=$ cajueiro; $\mathrm{Gr}=$ gravioleira; $\mathrm{Uz}=$ umbuzeiro); ${ }^{1}$ Isolados de diversos hospedeiros com diferentes sintomas (MD = morte-descendente; $\mathrm{PP}=$ podridão-do-pedúnculo; $\mathrm{PPH}=$ podridão-preta-das-hastes; $\mathrm{PSF}=$ podridão-seca-das-folhas; $\mathrm{RS}=$ resinose); ${ }^{2}$ Altitude dos pontos em que os isolados de $L$. theobromae foram coletados.
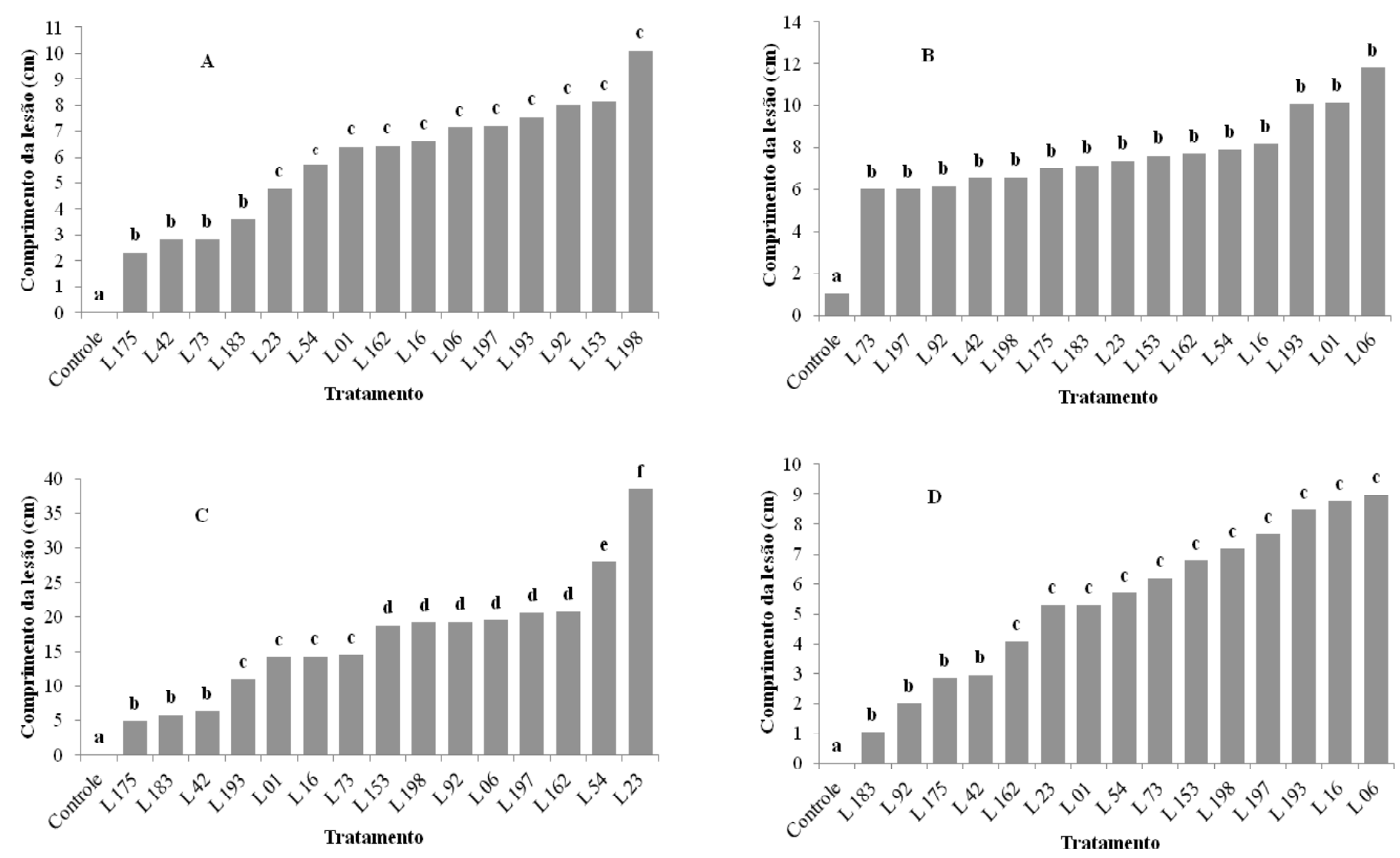

Figura 2. Crescimento médio das lesões em mudas inoculadas com os isolados de Lasiodiplodia theobromae: (A) cajazeira (Spondias mombin L.), CV (\%) $=15,67$; (B) cajueiro (Anacardium occidentale L.), CV $(\%)=19,94 ;(\mathrm{C})$ gravioleira (Annona muricata L.), CV (\%) $=12,25 ;(\mathrm{D})$ umbuzeiro (Spondias tuberosa Arruda), CV (\%) =18,91. Médias seguidas pela mesma letra não diferem entre si pelo teste de Scott-Knott ao nível de 5\% de significância. 
percentual de reisolamento nos quatro hospedeiros variou entre 12,5 e $100 \%$ (Tabela 5 ), o que confirmou a não especificidade de $L$. theobromae (24). Observou-se que os isolados mais agressivos (Tabela 4) foram os que apresentaram o maior percentual de reisolamento (Tabela 5), sugerindo uma relação entre patogenicidade e crescimento saprofítico.

A característica endofítica de $L$. theobromae, citada anteriormente $(2,4,7,10,17,18,25,26)$ pode explicar o isolamento do fungo de plantas de cajueiro não inoculadas (Tabela 5).

Houve correlação positiva entre crescimento micelial em meio AP e crescimento micelial em meio BDA para os isolados de L. theobromae
(Tabela 6), mostrando que o comportamento dos isolados do fungo variou uniformemente nos dois meios de cultura testados. Como pode ser observado na Tabela 6 , houve correlação positiva entre a taxa média de crescimento micelial dos isolados e a média do comprimento da lesão em cajazeira, gravioleira e umbuzeiro. Destaque maior se faz à interação entre o crescimento micelial em BDA ou AP e o comprimento médio da lesão em umbuzeiro que se mostraram altamente correlacionados. Esses resultados apontam uma possibilidade de se estimar a variabilidade na agressividade de isolados de $L$. theobromae com base no crescimento micelial em meio de cultura.

Verificou-se correlação positiva entre comprimento de lesão em

Tabela 5. Percentual médio de reisolamento de Lasiodiplodia theobromae depois de inoculado em 4 espécies hospedeiras.

\begin{tabular}{|c|c|c|c|c|}
\hline \multirow{3}{*}{ Isolado* } & \multicolumn{4}{|c|}{ Reisolamento (\%) } \\
\hline & \multicolumn{4}{|c|}{ Hospedeiros } \\
\hline & Cajazeira & Cajueiro & Gravioleira & Umbuzeiro \\
\hline Controle & 0 & 50 & 0 & 0 \\
\hline L 01 (Cajaraneira) - RS & 100 & 87,5 & 50 & 100 \\
\hline L 06 (Coqueiro) - PSF & 100 & 100 & 100 & 100 \\
\hline L 16 (Cirigueleira) - MD & 100 & 87,5 & 75 & 100 \\
\hline L 23 (Umbu-caja) - MD & 100 & 100 & 75 & 100 \\
\hline L 42 (Mangueira) - MD & 87,5 & 62,5 & 12,5 & 50 \\
\hline L 54 (Umbu) - MD & 100 & 87,5 & 87,5 & 100 \\
\hline L 73 (Aceroleira) - MD & 100 & 87,5 & 87,5 & 100 \\
\hline L 92 (Cajazeira) - MD & 62,5 & 37,5 & 50 & 62,5 \\
\hline L 153 (Gravioleira) - MD & 100 & 25 & 75 & 87,5 \\
\hline L 162 (Ateira) - MD & 100 & 87,5 & 75 & 100 \\
\hline L 175 (Cajueiro Gigante) - MD & 100 & 37,5 & 37,5 & 75 \\
\hline L 183 (Cajueiro Gigante) - RS & 75 & 25 & 12,5 & 100 \\
\hline L 193 (Abacateiro) - MD & 100 & 100 & 12,5 & 87,5 \\
\hline L 197 (Cajueiro Gigante) - PPH & 100 & 100 & 100 & 87,5 \\
\hline L 198 (Mamoeiro) - PP & 100 & 100 & 62,5 & 100 \\
\hline
\end{tabular}

* Isolados de diversos hospedeiros com diferentes sintomas $(\mathrm{MD}=$ morte-descendente; $\mathrm{PP}=$ podridão-do-pedúnculo; $\mathrm{PPH}=$ podridão-preta-das-hastes; PSF = podridão-seca-das-folhas; $\mathrm{RS}=$ resinose).

Tabela 6. Coeficiente de correlação de Pearson para os valores médios das variáveis morfoculturais, patogênicas e geográficas dos isolados de Lasiodiplodia theobromae estudados.

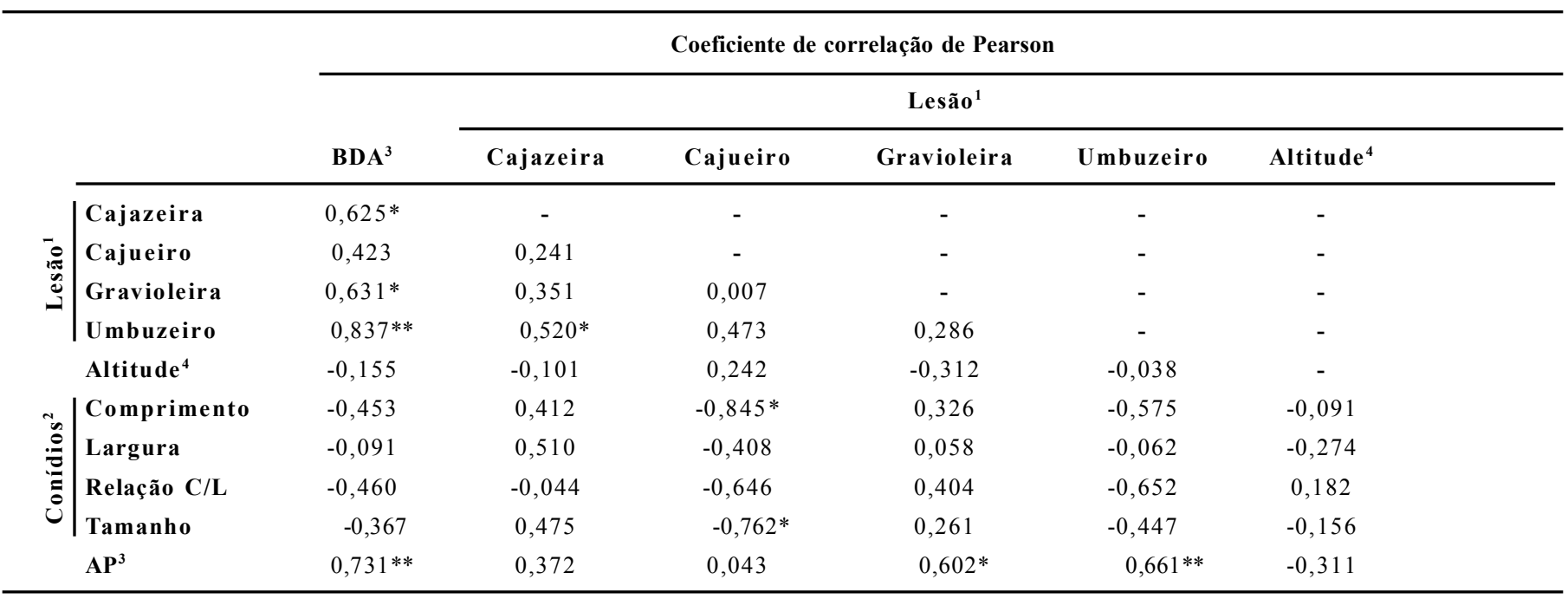

$(*, * *)$ Significativo ao nível de $5 \%$ e $1 \%$ de probabilidade, respectivamente, pelo teste $\mathrm{t} ;{ }^{1}$ Comprimento médio das lesões em mudas de 4 hospedeiros inoculadas com $L$. theobromae; ${ }^{2}$ Características morfológicas de conídios de L. theobromae (Relação $\mathrm{C} / \mathrm{L}=$ relação carbono/nitrogênio; Tamanho $=$ soma do comprimento com a largura do conídio); ${ }^{3}$ Crescimento micelial de L. theobromae em meios de cultura (AP = agar-acícula; BDA = batata-dextrose-agar); ${ }^{4}$ Altitude dos pontos em que os isolados de $L$. theobromae foram coletados. 
umbuzeiro e comprimento de lesão em cajazeira (Tabela 6). O fato de ambos os hospedeiros pertencerem ao mesmo gênero e apresentarem níveis de resistência similares para os diferentes isolados poderia explicar esses resultados, mostrando que os isolados apresentam níveis de patogenicidade semelhantes para os dois hospedeiros. Fundamentado nisto, pode-se presumir a variabilidade na agressividade de isolados de L. theobromae nas duas espécies, estudando a interação do fungo com apenas um dos hospedeiros.

Este estudo confirmou a diversidade cultural e morfológica de uma população de L. theobromae obtida a partir de isolamentos de frutíferas tropicais, diversidade esta já descrita em diversos trabalhos com esse fungo. Todavia, mesmo que todos os isolados tenham sido capazes de infectar mudas lenhosas das quatro fruteiras tropicais inoculadas, diferenças em agressividade foram observadas, permitindo separar indivíduos mais agressivos e hospedeiros mais resistentes. Este é o primeiro estudo que combina dados culturais, morfológicos e patogênicos de uma população de L. theobromae, importante patógeno de frutíferas tropicais. Estudos posteriores, utilizando um maior número de espécies hospedeiras e de isolados do patógeno, são necessários para uma maior caracterização dos diversos patossistemas que envolvem esse fungo.

\section{AGRADECIMENTOS}

À Coordenação de Aperfeiçoamento de Pessoal de Nível Superior (CAPES) e ao Conselho Nacional de Desenvolvimento Científico e Tecnológico (CNPq), pelo apoio financeiro.

\section{REFERÊNCIAS}

1. Abdollahzadeh, J.; Javadi, A.; Mohammadi-Goltapeh, E.; Zare, R.; Phillips, A.J.L. Phylogeny and morphology of four new species of Lasiodiplodia from Iran. Persoonia, Leiden, v.25, p.110,2010 .

2. Cardoso, J.E.; Bezerra, M.A.; Viana, F.M.P.; Sousa, T.R.M.; Cysne, A.Q.; Farias, F.C. Ocorrência endofítica de Lasiodiplodia theobromae em tecidos de cajueiro e sua transmissão por propágulos. Summa Phytopathologica, Botucatu, v.35, n.4, p.262-266, 2009.

3. Cardoso, J.E.; Freire, F.C.O.; Sá, F.T. Disseminação e controle da resinose em troncos de cajueiro decepados para substituição de copa. Fitopatologia Brasileira, Brasília, v.23, n.1, p.48-50, 1998.

4. Cardoso, J.E.; Paiva, J.R.; Cavalcanti, J.J.V.; Santos, A.A.; Vidal, J.C. Evaluation of resistance in dwarf cashew to gummosis in northeastern Brasil. Crop Protection, Kent, v.25, p.855-859, 2006.

5. Cardoso, J.E.; Santos, F.J.S.; Vidal, J.C.; Sousa, R.N.M. Influência da poda e da lâmina de água de irrigação na produção e na incidência da podridão-seca em ateira. Fortaleza: Centro Nacional de Pesquisa de Agroindústria Tropical/EMBRAPA, 2004. 17 p. (Boletim de Pesquisa e Desenvolvimento, 15).

6. Cardoso, J.E.; Viana, F.M.P.; Cysne, A.Q.; Farias, F.C.; Sousa, R.N.M. Clone Embrapa 51: uma alternativa para a resistência à resinose-do-cajueiro. Fortaleza: Centro Nacional de Pesquisa de Agroindústria Tropical/EMBRAPA, 2007. 3 p. (Comunicado Técnico, 130).

7. Cardoso, J.E.; Vidal, J.C.; Freire, F.C.O.; Montenegro, A.A.T.; Santos, A.A. Métodos de proteção do cajueiro contra a resinose durante o processo de substituição de copa. Fitopatologia Brasileira, Brasília, v.25, Suplemento, p.457-457, 2000 (Resumo).

8. Cardoso, J.E.; Vidal J.C.; Santos, A.A.; Freire, F.C.O.; Viana, F.M.P. First report of black branch dieback of cashew caused by Lasiodiplodia theobromae in Brazil. Plant Disease, St. Paul, v.86, p.558-558, 2002.

9. Cardoso, J.E.; Wilkinson, M.J. Development and characterisati- on of microsatellite markers for the fungus Lasiodiplodia theobromae. Summa Phytopathologica, Botucatu, v.34, n.1, p.5557, 2008.

10. Farias, F.B. Detecção da diversidade e associação de Lasiodiplodia theobromae com o cajueiro utilizando marcadores microssatélites. 2008. 42 f. Dissertação (Mestrado em Agronomia/Fitotecnia) - Departamento de Fitotecnia, Centro de Ciências Agrárias, Universidade Federal do Ceará, Fortaleza.

11. Freire, F.C.O.; Cardoso, J.E.; Viana, F.M.P.; Martins, M.V.V. Status of Lasiodiplodia theobromae as a plant pathogen in Brazil. Essentia, Sobral, v.12, n.2, p.53-71, 2011.

12. Freire, F.C.O.; Viana, F.M.P.; Cardoso, J.E.; Santos, A.A. Novos hospedeiros dos fungo Lasiodiplodia theobromae no estado do Ceará. Fortaleza: Centro Nacional de Pesquisa de Agroindústria Tropical/EMBRAPA, 2004. 6 p. (Comunicado Técnico, 91).

13. Halfeld-Vieira, B.A.; Nechet, K.L.; Souza, G.R. Influência de meios de cultura e regimes de luz na esporulação e crescimento micelial de Lasiodiplodia theobromae. Boa Vista: Centro de Pesquisa Agroflorestal de Roraima/EMBRAPA, 2007. 14 p. (Boletim de Pesquisa e Desenvolvimento, 2).

14. Lins, S.R.O.; Alves, E.; Oliveira, S.M.A. Estudos da interação Lasiodiplodia theobromae $\mathrm{x}$ mangueira caracterização morfológica de isolados do patógeno. Acta Microscopica, Caracas, v.19, n.3, p.221-231, 2010.

15. Melo, J.G.M. Diversidade genética de Lasiodiplodia theobromae associado ao cajueiro. 2010. 60 f. Dissertação (Mestrado em Agronomia/Fitotecnia) - Departamento de Fitotecnia, Centro de Ciências Agrárias, Universidade Federal o Ceará, Fortaleza.

16. Menezes, M.; Muniz, M.F.S.; Queiroz, F.M. Podridão da haste do mamoeiro "Sunrise-solo" causada por Botryodiplodia theobromae no estado de Alagoas. Summa Phytopathologica, Botucatu, v.23, p.44-45, 1997.

17. Mohali, S.; Burgess, T.I.; Wingfield, M.J. Diversity and host association of the tropical tree endophyte Lasiodiplodia theobromae revealed using simple sequence repeat markers. Forest Pathology, Berlin, v.35, p.385-396, 2005.

18. Mullen, J.M.; Gilliam, C.H.; Hagan, A.K.; Morgan-Jones, G. Canker of dogwood caused by Lasiodiplodia theobromae, a disease influenced stress or cultivar selection. Plant Disease, St. Paul, v.75, p.886-889, 1991.

19. Oliveira, J.; Alexandre, E.R.; Silva, E.K.C.; Silva, R.L.X.; Oliveira, S.M.A. Estudos do crescimento micelial sobre isolados de $\mathrm{La}$ siodiplodia theobromae. In: Jornada de ensino, pesquisa e extensão, 5., 2010, Recife. Resumos. Recife: UFRPE, 2010. p.3-3.

20. Pereira, A.L.; Silva, G.S.; Ribeiro, V.Q. Caracterização fisiológica, cultural e patogênica de diferentes isolados de Lasiodiplodia theobromae. Fitopatologia Brasileira, Brasília, v.31, p.572-578, 2006.

21. Punithalingam, E. Botryodiplodia theobromae. Description of Pathogenic Fungi and bacteria. Kew: Commonwealth Mycological Institute, n.519, 1976. 3 p.

22. Punithalingam, E. Plant diseases attributed to Botryodiplodia theobromae. Vaduz: Pat. J. Cramer, 1980. 123 p.

23. Ram, C. Características culturais, esporulação e violência do "strain" do Botryodiplodia theobromae, agente causal da queima-das-folhas do coqueiro (Cocos nucifera). Fitopatologia Brasileira, Brasília, v.18, p.143-146, 1993.

24. Rodrigues, R. Caracterização morfológica e patológica de Lasiodiplodia theobromae (Pat.) Griffon \& Maubl., agente causal das podridões de tronco e rázes da videira. 2003. 53 f. Dissertação (Mestrado em Agricultura Tropical e Subtropical) - Instituto Agronômico de Campinas, Campinas.

25. Rondón, V.M.; González, M.R. Micobiota endofítica asociada al cultivo Del mango 'Haden' (Mangifera indica L.) en el oriente de Venezuela. Revista UDO Agrícola, Monagas, v.9, n.2, p.393402,2009

26. Santos, A.A.; Cardoso, J.E.; Freire, F.C.O. Fungos associados a sementes de gravioleira e de ateira no Estado do Ceará Fortaleza: Centro Nacional de Pesquisa de Agroindústria Tropical/EMBRAPA, 2000. 11 p. (Boletim de Pesquisa e Desenvolvimento, 33). 
27. Tavares, S.C.C.H. Epidemiologia e manejo integrado de Botryodiplodia theobromae - situação atual no Brasil e no mundo. Fitopatologia Brasileira, Brasília, v.27, p.46-52, 2002.

28. Tavares, S.C.C.H. Principais doenças da mangueira e alternativas de controle. Distrito Federal: Centro de Pesquisa Agropecuária do Trópico Semiárido/EMBRAPA, 1995. (Informações técnicas sobre a cultura da manga no Semi-Árido brasileiro).

29. Tavares, S.C. C.H.; Barreto, D.S.B.; Amorim, L.R. Levantamento do comportamento de Botryodiplodia theobromae em videira na região semi-árida. In: Congresso Brasileiro de Fruticultura, 13.,
1994, Bahia. Anais. Salvador: Sociedade Brasileira de Fruticultura, 1994. p.933-934.

30. Úrbez-Torres, J.R.; Gubler, W.D. Pathogenicity of Botryosphaeriaceae species isolated from grapevine cankers in California. Plant Disease, St. Paul, v.93, n.6, p.584-592, 2009.

31. Úrbez-Torres, J.R.; Leavitt, G.M.; Guerreiro, J.C.; Guevara, J.; Gubler, W.D. Identification and pathogenicity of Lasiodiplodia theobromae and Diplodia seriata, the causal agents of bot canker disease of grapevines in Mexico. Plant Disease, St. Paul, v.92, n.4, p.519-529, 2008 